\title{
Etiological factors of abnormal uterine bleeding according to PALM- COEIN classification in perimenopausal women in a tertiary care centre
}

\author{
Nishi Mitra*, Pooja Patil, Ayushi Sethia
}

Department of Obstetrics and Gynecology, L. N. Medical College and J. K. Hospital, Bhopal, Madhya Pradesh, India

Received: 25 December 2019

Accepted: 04 January 2020

*Correspondence:

Dr. Nishi Mitra,

E-mail: doctornishi2001@yahoo.com

Copyright: () the author(s), publisher and licensee Medip Academy. This is an open-access article distributed under the terms of the Creative Commons Attribution Non-Commercial License, which permits unrestricted non-commercial use, distribution, and reproduction in any medium, provided the original work is properly cited.

\begin{abstract}
Background: Perimenopause is described as years prior to menopause that encompasses the change from normal ovulatory cycle to cessation of menses, ending 12 months after the last menses. International federation of gynaecology and obstetrics (FIGO) developed a new classification PALM-COEIN in order to standardize the factors associated with AUB. It classifies AUB as polyp, adenomyosis, leiomyoma, malignancy and hyperplasia (PALM) structural abnormalities Coagulopathy, ovulatory dysfunction, endometrial, iatrogenic, not yet classified (COEIN) unrelated to structural abnormalities. Objectives of this study were to categorise the causes of AUB in perimenopausal women in context to PALM COEIN classification system. Correlation of co-morbities (diabetes, hypertension and thyroid disorders) with AUB in perimenopausal age group.

Methods: This is a retrospective study from the month of May 2019 to October 2019, considering 100 patients of perimenopausal age group (40 to 55 years of age group) in J. K. Hospital Bhopal, Madhya Pradesh with complaints of abnormal uterine bleeding, admitted in gynae ward.

Results: Most of the patients in the current study were between 45-50 years of age i.e. 44\%. Menorrhagia was the commonest menstrual disorder encountered in 52\% of patients. As per FIGO; AUB-L constituted 42\% AUB-O constituted 12\%, AUB-P constituted 11\%, AUB-A 10\%, AUB-M constituted 8\% AUB-E constituted 8\%, not yet classified constituted $4 \%$ of total cases.

Conclusions: AUB (PALM-COEIN) for causes of abnormal uterine bleeding classification was very useful in categorizing cases of AUB. It suggests that etiology of AUB and also gives place for presence of multiple factors as a cause of AUB in a particular case.
\end{abstract}

Keywords: Abnormal uterine bleeding, Adenomyosis, Leiomyoma, Menorrhagia, PALM COEIN, Perimenopause

\section{INTRODUCTION}

Perimenopause is described as transitional years prior to menopause that encompasses the change from normal ovulatory cycle to cessation of menses.

Abnormal uterine bleeding (AUB) is the commonest menstrual problem during peri menopause. AUB is a bleeding pattern differing from normal menstrual pattern or after menopause in frequency, duration, and amount of blood flow. ${ }^{1}$

Earlier there was a lot of discrepancy in the nomenclature used to describe abnormal uterine bleeding (AUB). The development of consistent and universally accepted nomenclature was a step toward rectifying this unsatisfactory circumstance, thus PALM COEIN classification was adopted by FIGO (international federation of gynaecology and obstetrics) in order to 
standardize the factors associated with AUB. It classifies AUB as polyp, adenomyosis, leiomyoma, malignancy and hyperplasia (PALM) - structural abnormalities. Coagulopathy, ovulatory dysfunction, endometrial, iatrogenic, not yet classified (COEIN) - unrelated to structural abnormalities. $^{2}$

Another requirement is the development of a classification system, on several levels for the causes of AUB, which can be used by clinicians, investigators, and even patients to facilitate communication, clinical care, and research and presents for consideration of the PALMCOEIN classification system for AUB, which has been approved by the International Federation of gynaecology and obstetrics (FIGO) Executive Board as a FIGO classification system. DUB should be replaced by coagulopathy, endometrial and ovulatory disorders. ${ }^{3}$

\section{Terminologies used for diagnosis that are now included in $A U B$}

- Amenorrhea: The absence of menstrual bleeding for more than 6 months

- Breakthrough bleeding: intermenstrual bleeding that occur despite the use of exogenous hormones

- Dysmenorrhea: painful menses

- Menorrhagia: prolonged menstrual bleeding that is excessive in amount, duration or both that occurs in regular intervals

- Metrorrhagia: bleeding between menses

- Oligomenorrhea: bleeding that occurs less frequently than every 35 days

- Polymenorrhea: bleeding that occurs more often than 21 days

- Postmenopausal bleeding: uterine bleeding occurring more than 12 months after the last menstrual period of a menopausal women.

Histological assessment remains the cornerstone in the current practice in patients of AUB as it provides the diagnosis and guides for the correct management plan.

Abnormal uterine bleeding affects 10 to 30 percent of reproductive-aged women and up to 50 percent of perimenopausal women.,

\section{Transitions are enumerated below ${ }^{6}$}

- Changes in menstrual patterns includes: typical Shorter cycles (by 2-7 days), longer cycles possible, Irregular bleeding with spotting

- Vasomotor symptoms: hot flushes Night sweats, Sleep disturbances

- Psychological and metal disturbances: worsening of premenstrual symptoms, depression, mood swings, irritability, loss of concentration, and poor memory

- Sexual dysfunction: vaginal dryness, decreased libido, painful intercourse. Somatic symptoms headache, dizziness, palpitations, breast pain and enlargement, joint aches and back pain

- Other symptoms: urinary incontinence, dry, itchy skin, weight gain

- Causes of perimenopausal bleeding range from commonly anovulatory cycles; but heightened concerns about pathologic anatomy (hyperplasia, polyps, submucous myomas and even frank carcinoma) have made invasive diagnostic procedures common requirement in addition to clinical $^{3}$

- Age of onset of perimenopause in $95 \%$ women is 39 to 51 years. Average age of onset is 46 years. The duration of perimenopausal transition is 2 to 8 years. The average duration of menopausal transition is 5 years. Indian women menopause occurs at 45 years and thus 40 years can be taken as lower limit of perimenopause. ${ }^{7}$ AUB is the commonest menstrual problem during perimenopause which is defined as the period of 2-8 years preceding menopause and 1 year after the final menses. Follicular development at this time has been demonstrated to be erratic, with consequent variability in oestrogen levels and an increased percentage of anovulatory cycles making them more likely to experience abnormal uterine bleeding. ${ }^{8}$

\section{METHODS}

This is a retrospective study from the month of May 2019 to October 2019, considering 100 patients of perimenopausal age group (40 to 55 years of age group) in J. K. Hospital Bhopal, Madhya Pradesh with complaints of abnormal uterine bleeding, admitted in gynae ward.

Data collection from past files was done and patients with complaints of AUB classified according to PALMCOEIN classification.

Correlation made with respect to comorbidities, such as diabetes, hypertension and thyroid disorders.

A proforma was filled by obtaining the detailed history from the file of the patient which included: symptoms like dysmenorrhea, dyspareunia, postcoital bleeding intermittent spotting, unhealthy discharge, foul smelling discharge, heaviness and discomfort in the lower abdomen, backache and any other constitutional symptoms.

A detailed obstetric history was also noted including total number of deliveries weather normal/caesarean/forceps, no. of abortions. H/o sterilization, contraception, especially IUCDs and OC Pills was also filled. Any postpartum / post-operative complications, past history of similar episode was noted and the details of the treatment given, whether hormonal/surgical was also taken in account. Personal, past and family history was also recorded. In every patient per speculum examination and 
per vaginal examination performed was recorded. According to findings on history and clinical examination provisional clinical diagnosis was made, which was later confirmed by ultrasonography and histopathology.

\section{Inclusion criteria}

- All women in perimenopausal age group admitted in gynae ward with complaint of Abnormal uterine bleeding.

\section{Exclusion criteria}

- All women with abnormal uterine bleeding with any adnexal pathology, AUB With IUCD in situ, AUB with any other gynaecological comorbidities such as uterine prolapse.

\section{Statistical analysis}

Incidence rate

$$
=\frac{\begin{array}{c}
\text { Patients presenting with different classes of AUB } \\
\text { (PALM }- \text { COEIN) }
\end{array}}{\begin{array}{c}
\text { Total no of patients } \\
\text { (sample size })
\end{array}} \times 100
$$

The date was entered in Microsoft Excel 2016 (MSO) and incidence rate was calculated using the above formula.

\section{RESULTS}

Forty four percent women were in 45-50 years, $32 \%$ in 40-45 years and $24 \%$ were in 50-55 years age group (Table 1). Most of women were multiparous having 2-4 children, i.e. $45 \%$ (Table 2). Hypertension as a comorbidity was present in $18 \%$ of the patients (Table 3 ). Majority of women came with chief complaint of menorrhagia (52\%) followed by metrorrhagia (16\%) (Table 4).

Table 1: Distribution of cases according to age.

\begin{tabular}{|lll|}
\hline Age group of patients & No. of patients & $\%$ \\
\hline $40-45$ & 32 & $32 \%$ \\
\hline $45-50$ & 44 & $44 \%$ \\
\hline $50-55$ & 24 & $24 \%$ \\
\hline
\end{tabular}

Table 1 shows that about $44 \%$ of patients of the perimenopausal age group belong to 45-50 years followed by $32 \%$ of patients belonging to $40-45$ years of age group. However, AUB in our study was found to be less common in the age group of 50-55 years.

Table 2 shows that AUB was more common in multiparous patients than in primiparous patients. Among the total AUB patients only $28 \%$ were primipara and the rest $72 \%$ were multipara.
Table 2: Distribution of patients according to parity.

\begin{tabular}{|lll|}
\hline Parity & No. of patients & $\%$ \\
\hline$<2$ & 28 & $28 \%$ \\
\hline $2-4$ & 45 & $45 \%$ \\
\hline$>4$ & 27 & $27 \%$ \\
\hline
\end{tabular}

Table 3, in our study hypertension was found in $18 \%$ patients, diabetes in $12 \%$ patients with AUB, hypothyroidism in $6 \%$ patients of AUB.

Table 3: Distribution of patients according to comorbidities.

\begin{tabular}{|ll|}
\hline Comorbidities & No. of patients with AUB \\
\hline Diabetes & $12 \%$ \\
\hline Hypertension & $18 \%$ \\
\hline Hypothyroidism & $6 \%$ \\
\hline
\end{tabular}

Table 4, shows that menorrhagia was the commonest menstrual disorder encountered in 52 cases $(52 \%)$, followed by metrorrhagia $16 \%$, menometrorrhagia $12 \%$, hypomenorrhea $10 \%$, polymenorrhea $8 \%$, metropathica hemorrhagica in $2 \%$ cases.

\section{Table 4: Distribution of cases according to} their symptoms.

\begin{tabular}{|lll|}
\hline Menstrual complaint & $\begin{array}{l}\text { No. of } \\
\text { patients }\end{array}$ & $\%$ \\
\hline Menorrhagia & 52 & $52 \%$ \\
\hline Metrorrhagia & 16 & $16 \%$ \\
\hline menometrorrhagia & 12 & $12 \%$ \\
\hline Polymenorrhhea & 8 & $8 \%$ \\
\hline Hypomenorrhea & 10 & $10 \%$ \\
\hline $\begin{array}{l}\text { Amenorrhea followed by } \\
\text { prolonged bleeding per vaginum } \\
\text { (metropathica hemorrhagica) }\end{array}$ & 2 & $2 \%$ \\
\hline
\end{tabular}

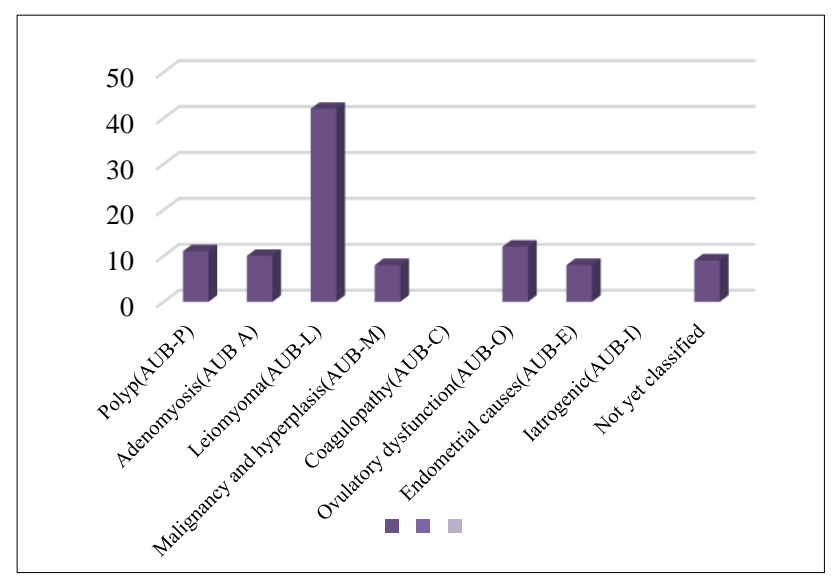

Figure 1: Incidence of causes of abnormal uterine bleeding.

Figure 1 shows that in our study $42 \%$ cases had leiomyoma which is the leading cause of AUB in 
perimenopausal patients. AUB-O constituted 12\%, AUBP constituted 11\%, AUB-A 10\%, AUB-M constituted $8 \%$ AUB-E constituted $8 \%$, not yet classified constituted $4 \%$ of total cases.

\section{DISCUSSION}

Previously, there use to be a general inconsistency in the nomenclature to describe AUB (abnormal uterine bleeding). As there was no universally accepted format to describe the commonest gynaecological problem. Thus, there was an urgent need for the development of consistent and universally accepted nomenclature of abnormal uterine bleeding. So, development of PALMCOEIN classification was a step toward to rectify this unsatisfactory circumstance. This manuscript describes an ongoing process designed to achieve these goals, and presents for consideration of the PALM-COEIN (polyp; adenomyosis; leiomyoma; malignancy and hyperplasia; coagulopathy; ovulatory dysfunction; endometrial; iatrogenic; and not yet classified) classification system for AUB, which has been approved by the International Federation of Gynecology and Obstetrics (FIGO) Executive board as a FIGO classification system. ${ }^{9,10}$ This universal classification system for the causes of AUB can be used by all the clinicians, investigators, and even patients worldwide to facilitate communication, clinical care, and research. In our study, we studied retrospectively, 100 cases of AUB in the perimenopausal age group (40-55 year). Most of the patients with AUB in the present study were between $45-50$ years i.e. $44 \%$. There were $32 \%$ patients in $40-45$ years' age group, $24 \%$ in 50-55 years' age group. AUB in our study was found to be less common in the age group of 50-55 years. As found in the study of Urvashi et al where AUB was found common in 44-47 years age group. ${ }^{11}$ AUB was more common in multiparous patients than in primiparous patients. Similar results have been shown by Dr. Kumar Suneet in his study. ${ }^{12}$ In our study hypertension was found in $18 \%$ patients, followed by diabetes in $12 \%$ patients of AUB, followed by hypothyroidism in $6 \%$ patients. In the study done by Subedi et al, thyroid disorders was present in $10.6 \%$ patients with AUB. Thus, there stands an association among non-structural causes of AUB and medical disorders. ${ }^{13}$ Menorrhagia was the commonest menstrual disorder encountered in 52 cases $(52 \%)$, followed by metrorrhagia $16 \%$, menometrorrhagia $12 \%$, hypomenorrhea $10 \%$, polymenorrhea $8 \%$, metropathica hemorrhagica in $2 \%$ cases. Our study correlated well with study done by Pillai GS et al. ${ }^{9}$ In our study $42 \%$ cases had leiomyoma which was found to be the leading cause of AUB in perimenopausal patients. AUB-O constituted 12\%, AUB-P constituted 11\%, AUBA 10\%, AUB-M constituted 8\% AUB-E constituted 8\%, not yet classified constituted $4 \%$ of total cases. Similarly, Study done by Singh A et al also showed leiomyoma as the leading cause of AUB followed by ovulatory cause, various other researchers also supported the study. ${ }^{4,14,15}$ Histopathological pattern of endometrium in women with AUB is quite variable depending upon age and parity.
Higher association of AUB is seen with submucosal type, compared to intramural and subserous type. In perimenopausal years, ovulatory disorders are common due to derangements in the hypothalamo-pituitaryovarian axis resulting in derangements of follicular maturation, ovulation or corpus luteum formation, anovulatory cycles are most frequent, and chronic anovulation is associated with an irregular and most unpredictable pattern of bleeding. This explains why ovulatory disorders were found to be the second most common cause of AUB in this study and many other studies. The other important cause of AUB was Adenomyosis. The unopposed oestrogenic action on the endometrium in the anovulatory cycles found in perimenopausal women predisposes them to develop hyperplasia and eventually endometrial carcinoma. This is due to the fact that perimenopausal women have more anovulatory cycles. ${ }^{3}$ In the majority of women with true anovulatory bleeding, the menstrual history alone can establish the diagnosis with sufficient confidence and treatment can begin without any additional lab evaluation or imaging. In frequent, irregular, unpredictable menstrual bleeding that varies in amount, duration and character and is not preceded by any recognisable or consistent pattern are not difficult to interpret. Conversely, regular monthly periods that are heavy or prolonged are more likely related to an anatomical cause or a bleeding disorder. ${ }^{8}$ This may be because most women in this category tend to have no definable cause of AUB.

\section{CONCLUSION}

In perimenopausal women after clinical examination (speculum and bimanual) and Pap smear, ultrasonography should be first investigation as it is easily available, less expensive, safe and non-invasive method. It excludes those adnexal or myometrial pathologies which may be missed in clinical assessment.

Funding: No funding sources

Conflict of interest: None declared

Ethical approval: The study was approved by the Institutional Ethics Committee

\section{REFERENCES}

1. Singh K, Agarwal C, Pujani M, Raychaudhuri S, Sharma N, Chauhan V, et al. A clinicopathological correlation of international federation of gynecology and obstetrics's PALM-COEIN classification of abnormal uterine bleeding: Indian scenario. J -Life Health. 2019;10(3):147.

2. Munro MG, Critchley HO, Fraser IS, FIGO Menstrual Disorders Committee, Haththotuwa R, Kriplani A, Bahamondes L, Füchtner C, Tonye R, Archer D, Abbott J. The two FIGO systems for normal and abnormal uterine bleeding symptoms and classification of causes of abnormal uterine bleeding 
in the reproductive years: 2018 revisions. Int $\mathbf{J}$ Gynecol Obstet. 2018;143(3):393-408.

3. Palwade JM, Borole CS. A study of causes of abnormal uterine bleeding with respect to FIGO classification in the patients at perimenopausal age. Int Med J. 2016;3(11):5.

4. Sun Y, Wang Y, Mao L, Wen J, Bai W. Prevalence of abnormal uterine bleeding according to new International Federation of Gynecology and Obstetrics classification in Chinese women of reproductive age: a cross-sectional study. Medicine (Baltimore). 2018;97(31):e11457.

5. Prentice A. When does heavy flow merit treatment? Practitioner. 2000;244:174-9.

6. Jones HW, Rock JA, Te Linde's Operative gynecology, 11th ed. 2015:555.

7. Singh S, Yadav P, Rani R, Verma U. Diagnostic approach in perimenopausal women with abnormal uterine bleeding. J SAFOMS. 2014;2(1):12-4.

8. Mishra D, Sultan S. FIGO's PALM-COEIN Classification of abnormal uterine bleeding: a clinico-histopathological correlation in Indian setting. J Obstet Gynecol India. 2017;67(2):119-25.

9. Sethi B, Dhaded AV, Mathur PR. Dysfunctional uterine bleeding. J Obstet Gynecol India. 2002;52(3):87-9.

10. Munro MG, Critchley HOD, Broder. FIGO classification system (PALM-COEIN) for causes of abnormal uterine bleeding in nongravid women of reproductive age. Int J Gynecol Obstet. 2011;113:313.

11. Verma U, Garg R, Singh S, Yadav P, Rani R. Diagnostic Approach in Perimenopausal Women with Abnormal Uterine Bleeding. J South Asian Fed Menopause Soc. 2014 Jan 1;2:12-4.

12. Kumar S. Clinicopathological study of abnormal uterine bleeding in North Indian patients. Asian J Biomed Pharma Sci. 2016;6(53):50-1.

13. Subedi S, Banerjee B, Manisha C. Thyroid disorders in women with dysfunctional uterine bleeding. J Pathol Nepal. 2016 Sep 24;6(12):1018-20.

14. Singh A, Choudhary A. A study of PALM-COEIN Classification of Abnormal Uterine Bleeding (AUB) in Perimenopausal Women at a Tertiary Care Teaching Hospital. J Med Sci Clinical Res. 2018;6(6):287-92.

15. Sabbioni L, Zanetti I, Orlandini C, Petraglia F, Luisi S. Abnormal uterine bleeding unrelated to structural uterine abnormalities: management in the perimenopausal period. Minerva Ginecol. 2017;69(1):75-83.

Cite this article as: Mitra N, Patil P, Sethia A.

Etiological factors of abnormal uterine bleeding according to PALM- COEIN classification in perimenopausal women in a tertiary care centre. Int $\mathbf{J}$ Reprod Contracept Obstet Gynecol 2020;9:799-803. 